\title{
As transformações no radiojornalismo no ecossistema móvel: uma radiomorfose possível
}

\section{THE TRANSFORMATIONS IN RADIOJOURNALISM IN THE MOBILE ECOSYSTEM: A POSSIBLE RADIOMORPHOSIS}

\section{Alciane Baccin}

Professora do Mestrado Profissional em Jornalismo do FIAM-FAAM - Centro Universitário.

Doutora em Comunicação e Informação (UFRGS) e em Ciências da Comunicação (UBI/Portugal).

E-mail: alcianebaccin@gmail.com

\section{Maicon Kroth}

Doutor em Ciências da Comunicação pela Universidade do Vale do Rio dos Sinos. Pósdoutorado em Ciências da Comunicação pela Universidade da Beira Interior e professor da Universidade Federal de Santa Maria.

E-mail: maiconeliask@gmail.com

Recebido em 14 de novembro de 2017. Aprovado em 31 de janeiro de 2018.

\section{Resumo}

Este artigo analisa as características das narrativas jornalísticas no aplicativo da TSF Rádio Notícias, de Lisboa, Portugal, em comparação com o site da emissora. Com base no referencial teórico-metodológico, são identificadas as mutações do radiojornalismo a partir das lógicas do ecossistema móvel. No aplicativo da rádio $\mathrm{TSF}$, os conteúdos analisados na amostra revelaram que a narrativa radiofônica ainda não apresenta modificações da versão web para mobile. A incorporação de narrativas multimidiáticas ocorre, mas o conteúdo é somente transposto para o app. Assim, a emissora ainda poderá explorar as características técnicas dos dispositivos móveis, adequando ainda mais a sua produção radiojornalística às lógicas do ecossistema digital, especialmente às demandas de consumo mobile.

Palavras-chave: Rádio. Jornalismo. Comunicação móvel. Digitalização. 


\section{Abstract}

This article analyzes characteristics of the journalistic narrative in the TSF Radio News app, from Lisbon, Portugal, compared with that of the radio station website. From a theoretical and methodological framework, radio journalism mutations founded on the logics of the mobile ecosystem were identified. In the app of the radio station TSF, the contents analyzed in the sample revealed that the radio narrative was still not adapted from the web version to the mobile version. The incorporation of multimediatic narratives occurs, but the content has simply been transposed into the app. Thus, the radio station may also explore the technical characteristics of mobile devices, being able to adapt its radio journalistic content production even more to the logics of the digital ecosystem, especially to the demands of mobile usage.

Keywords: Radio. Journalism. Mobile communication. Digitalization.

\section{Introdução}

O ecossistema midiático tem sido caracterizado por mudanças no processo de produção jornalística para tecnologias móveis e seus usos (SCOLARI et al., 2009). Nos últimos anos, a migração dos públicos para a Internet tornou evidente a necessidade de redirecionamento das dinâmicas de produção de conteúdo, e isso também ocorreu no campo jornalístico. Mas não bastaria apenas a preocupação em ressignificar a produção de conteúdo informativo, era também preciso deixá-lo atraente por meio de uma série de estratégias capazes de tornar a distribuição mais eficiente e despertar a atenção da audiência, com vistas a otimizar o consumo.

Nessas condições, viu-se que o processo de convergência jornalística potencializou a criação de novos formatos aos conteúdos jornalísticos. Salaverría, García Avilés e Masip (2010) entendem a convergência jornalística a partir de quatro dimensões: tecnológica, empresarial, profissional e de conteúdos ou editorial. Para os autores, uma das preocupações do setor midiático foi com o desenvolvimento de interfaces inovadoras. O uso de dispositivos móveis com acesso à Internet, cada vez mais usual pelos diferentes segmentos da sociedade, tornou necessária a exploração de características técnicas de smartphones e tablets, os quais exigiram adequações como novas linguagens e possibilidades de acesso à informação para um consumo cada vez mais personalizado dos conteúdos.

É sobre estes conteúdos e a dimensão tecnológica a que esta pesquisa vai ater-se, mas focada na emergência dos dispositivos para o consumo de notícias radiofônicas. O cenário da mobilidade tem se constituído desde a sua origem um objeto de interesse 
das empresas jornalísticas. Inclusive, mesmo antes da difusão dos smartphones e dos tablets, os dispositivos móveis sempre estiveram relacionados a possiblidades de consumo ubíquo de informação (AGUADO; CASTELLET, 2013), tanto na perspectiva da distribuição (com os dispositivos móveis como canais emergentes de notícias) como na produção (com os dispositivos móveis como ferramentas ubíquas para o registro dos acontecimentos e edição de notícias).

Tal contexto pode ser observado no terreno radiofônico, como evidencia Lopez (2009). Para a autora, hoje, o rádio informa conteúdos que não são somente o som, mas também, por meio de textos e imagens, reconfigurando os modos de produção de seus conteúdos. Assim, o interesse desta pesquisa está centrado em estudar as características dos conteúdos radiojornalísticos disponibilizados em um aplicativo móvel.

\section{Metodologia}

Focamos nosso estudo no aplicativo móvel para iPhone Operating System (iOS) ${ }^{1}$, da TSF Rádio Notícias de Lisboa, Portugal. Interessa-nos saber: o que o aplicativo da TSF traz de novo para o radiojornalismo? Neste sentido, a observação se centrou nos conteúdos disponibilizados pelo aplicativo da emissora entre 11 e 17 de outubro de 2015. A análise fundamentou-se, metodologicamente, em identificar conteúdos jornalísticos, levando-se em consideração sua estrutura narrativa, mediante categorias estruturadas com base em lógicas do ecossistema digital e móvel, trazidas por alguns pesquisadores que estudam o assunto e estão presentes no referencial teórico do texto.

Nesta investigação, o estudo de caso tem como foco o produto em si, especialmente o conteúdo jornalístico, ficando de fora da análise, pelas características do paper, as questões de produção e consumo da informação. $\mathrm{O}$ aplicativo para dispositivos móveis da TSF Rádio Notícias, de Lisboa, está disponível para os sistemas Android e IOS, sendo a análise realizada neste último. O app é gratuito e não demanda cadastro ou login do usuário. Em termos de gênero, o app apresenta uma arquitetura estruturada em torno de conteúdos jornalísticos informativos.

\section{A radiomorfose na era digital}

O ecossistema digital (AGUADO; FEIJÓO; MARTÍNEZ, 2013) afetou o rádio e o obrigou a uma redefinição nos modos de produzir informação. A partir de uma cultura

1 Trata-se de um sistema operacional móvel da Apple Inc. desenvolvido, essencialmente, para o iPhone e todos os outros produtos da marca (iPod touch, iPad e Apple TV). 
da portabilidade (KISCHINHEVSKY, 2008), o rádio organizou-se em torno de características da multimidialidade (SALAVERRÍA, 2005). Aos poucos, incorporou novos serviços e conteúdos (CEBRIÁN HERREROS, 2011), adequando seu caráter informativo às exigências dos novos consumidores, sobretudo os jovens, e reestabelecendo, a partir do processo de remediação (BOLTER; GRUSIN, 2001), seu caráter pessoal, móvel e ubíquo.

O telefone sempre foi um aliado do rádio para a produção de conteúdos e para interação com a audiência (DEL CANO; GONZÁLEZ-MOLINA, 2015). Mas a chegada dos dispositivos móveis, como o Iphone, em 2007, e o Ipad, em 2010, se constituíram como um território tecnológico definitivo para a radiomorfose (PRATA, 2008). De lá para cá, as emissoras radiofônicas buscam dar passos estratégicos para melhorar seus canais em plataformas móveis.

A chegada da terceira geração de telefonia móvel - celulares que propiciam ampla oferta de serviços de voz e dados, além de receberem sinais de rádio em Frequência Modulada (FM) e navegarem na Internet - surge como uma evidência de mudança cultural. Nessas condições, no ecossistema móvel, a redefinição do rádio ocorre não só em termos de negócios, mas, sobretudo, na alteração da sua abordagem de produção de conteúdos a partir da adequação aos modos de consumo contemporâneos.

A narrativa radiofônica vem sendo construída, no ambiente digital, com base na combinação de diferentes elementos como vídeos, fotos e textos, os quais se somam ao som. O rádio hipermidiático (LOPEZ, 2009), que fala em distintos suportes e que tenta, ainda, manter no áudio o seu foco, explora cada vez mais novas linguagens e formatos possibilitados pela hibridização de formas simbólicas desenvolvidas para a difusão em multiplataformas (FERRARETTO, 2010).

Essa potencialidade fez com que o rádio reconfigurasse a relação entre as emissoras e os ouvintes. Irrompe o prosumidor, ou seja, o ouvinte-internauta, que se torna ativo não somente no acesso e consumo dos conteúdos, mas na produção e na difusão com base nas apropriações que faz das tecnologias, já não havendo mais papéis separados entre produtores e consumidores, que passam a interatuar no processo.

As emissoras têm apostado cada vez mais na criação e utilização dos aplicativos (apps) para dispositivos móveis. O acesso à Internet por meio de Wireless Application Protocol (WAP), Wi-Fi e 3G ou 4G, possibilitando ouvir estações de todo o mundo em mobilidade, e, ainda, contando com conteúdos multimídia nos dispositivos móveis, reestrutura a esfera produtiva (rotinas e sujeitos envolvidos do processo de produção dos conteúdos). A transposição dos conteúdos hertzianos para a palma da mão dos ouvintes está cada vez mais relacionada à experiência tecnológica dos sujeitos, interferindo 
diretamente nas relações que os indivíduos estabelecem com as informações. Por meio de recursos multimídia disponibilizados nos aplicativos, a informação radiofônica tem o som e a imagem, é mais interativa, mais participativa e customizável.

A acessibilidade, umas das principais características do jornalismo para plataformas móveis, nunca foi tão reforçada desde a invenção dos pequenos rádios a pilha, carregados no bolso. O cenário convergente foi modificando os circuitos interativos organizados por meio da arquitetura dos apps, fazendo emergir o protagonismo das redes sociais, o que estimulou as possibilidades de interação e o compartilhamento de informações (ORTIZ SOBRINO, 2012). Isso dinamizou de maneira ainda mais eficaz a produção de conteúdos tanto das emissoras quanto da audiência (KROTH, 2012).

A interação constituída pelos diferentes canais oferecidos pelas emissoras através dos apps estimula a conversação, visando à construção de vínculos com a audiência (KROTH, 2012), potencializando ainda mais essa característica do rádio. Isso já se fazia no rádio hertziano, mas agora ganha novos contornos, a partir de uma conjuntura de interferências tecnológicas e da complexificação da narrativa radiofônica (LOPEZ, 2015).

O volume de conteúdos que circula entre os campos de produção e coprodução (diga-se os ouvintes) constitui um circuito. Em fluxo contínuo, as trocas de narrativas radiofônicas entre as gramáticas de produção e recepção (KROTH, 2012) colocam em marcha um novo conceito de comunidade de usuários, que se estrutura desde novas fórmulas de participação baseadas numa arquitetura de interatividade cada vez mais colaborativa.

A chamada economia dos apps (MANDEL, 2012) ainda está em plena evolução e não é fácil, por enquanto, articular coerentemente uma observação diante de um panorama tão complexo e dinâmico. Mas se pode afirmar que os serviços de informação, disponibilizados por meio dos aplicativos de emissoras de rádio, têm focado na instantaneidade, na proximidade, personalização e socialização (AGUADO; CASTELLET, 2013). Isso ocorre porque os aplicativos tornam mais direta a relação com o ouvinte-internauta, facilitando um melhor controle e uma maior eficácia da experiência de consumo, especialmente quando há a possibilidade de integrar suas próprias narrativas ao conteúdo consumido, por meio de comentários ou compartilhamentos, em tempo real e em condições ubíquas.

\section{Os dispositivos móveis no ecossistema midiático}

A ecologia dos meios (Media Ecology), proposta por Marshall McLuhan, Neil Postman e Walter Ong como uma metáfora aplicada à ideia de que a mídia constituiria uma espécie de ambiente circundante aos sujeitos e que este afetaria seus sistemas 
cognitivos e percepções sobre o mundo, admite algumas expansões conceituais à luz da própria evolução dos meios de comunicação.

Neste sentido, partimos do entendimento do que Canavilhas (2010) interpreta como "o novo ecossistema midiático". Segundo o autor, as mudanças no campo da informação, advindas de uma sociedade que se configura em rede, têm se caracterizado pelo desenvolvimento de um complexo sistema de relações entre os meios de comunicação, constituindo um ambiente em que novas formas de interação dos sujeitos com os conteúdos ocorrem, assim como mudanças no consumo midiático motivadas pela mobilidade.

Uma das principais características do ecossistema midiático é a profunda transformação em nível de produção de conteúdos, que pode ser compreendida à luz de uma mudança do chamado sistema pull, em que o consumidor busca as notícias, para um sistema push, no qual a informação vai ao encontro do consumidor (FIDALGO; CANAVILHAS, 2009), e tem a possibilidade de escolher como, quando e onde vai consumi-la. Aliada a essa característica, as mudanças são vislumbradas desde o consumo de informações, que passa a ser contínuo, móvel, global e individual, e, ainda, as novas possibilidades de interatividade incrementadas a partir do desenvolvimento tecnológico e que permite o consumidor da informação participar do processo produtivo dela.

Na ambiência do ecossistema midiático, a emergência de um “novo meio"(SCOLARI et al., 2009) - referindo aos dispositivos móveis - luta para construir seu próprio espaço, forçando a mídia a se adaptar para sobreviver ao cenário em movimento. Nesse sentido, a relevância das plataformas móveis tem sido estudada desde uma conjuntura midiática, a partir das dimensões institucional, tecnológica e cultural. As próprias características do ecossistema midiático contribuem para a formalização de uma interconexão de diferentes narrativas mediante o processo contínuo de mediamorfose (FIDLER, 1997).

A caracterização da comunicação móvel do ecossistema midiático deve ser articulada com base no entendimento da diferenciação do que são aplicações e conteúdos, partindo-se do entendimento de que as diferenças são pouco evidentes, ou seja, aplicações e conteúdos estariam intimamente conectados. Tanto os conteúdos quanto as aplicações são passíveis de uma classificação organizativa nas quais pode-se evidenciar as marcas características da comunicação móvel. Para Scolari, Aguado e Feijóo (2013), conteúdos disponibilizados em dispositivos móveis podem ser classificados segundo diversos critérios, a natureza, a relação com outros conteúdos e outros meios de comunicação, a forma de acesso e gestão. Das propostas de classificação que mais se consolidaram, segundo os autores, e as categorias mais evidentes são:

Gênero/propósito - Os conteúdos para aplicativos móveis podem se classificar segundo uma articulação organizada pela Teoria Funcionalista no início da Mass Communication Research, as quais definiram três grandes funções dos meios de comunicação: informar, 
persuadir e entreter. Nesse contexto, identificam-se diferentes categorias de conteúdos, desde notícias, publicidade e produtos destinados ao entretenimento, como livros, música, fotos etc. Origem/Adaptação - Feijóo et al. (2009) propõem a seguinte categorização:

- Conteúdos não adaptados - que não sofreram nenhum tipo de adaptação para o consumo móvel.

- Conteúdos adaptados - procedentes de diferentes meios de comunicação que foram adaptados para serem visualizados e utilizados em um dispositivo móvel. A adaptação pode incluir desde uma redução ou duração até um reenquadramento de uma imagem.

- Conteúdos originais ou específicos - estruturados especificadamente para dispositivos móveis.

- Conteúdos aumentados - aproveitam as propriedades dos sistemas móveis como estratégia para capturar o interesse do usuário.

Estratégia narrativa - Os conteúdos podem ser classificados em autônomos ou dependentes. Para Scolari, Aguado e Feijóo (2013), autônomos são aqueles conteúdos cuja interpretação não exige o consumo de um conteúdo complementar para compreendê-lo em sua totalidade. Já os dependentes são as produções que necessitam ser contextualizadas por outros conteúdos.

Origem narrativa - os conteúdos podem ser criados por um produtor oficial do mundo narrativo, ou seja, um jornalista, ou pelos usuários (o enunciador-destinatário que constitui o novo prosumidor).

Armazenamento/Acesso - capacidade de armazenamento dos conteúdos e acessibilidade a eles. Mesmo que existam conteúdos que se consomem ao vivo, via streaming, há outros que se consomem depois de descarregá-los (downloading) nos dispositivos móveis. Esta categoria também pode ser pensada a partir das características de atualização contínua e memória (PALACIOS, 2014).

A categorização anterior remete a unidades textuais de qualquer tipo, escrita, icônica, multimídia, interativa etc., capazes de transmitir significados e ampliar o conhecimento acerca dos conteúdos. É a integração entre conteúdos, computação e comunicação que constitui a identidade característica dos dispositivos móveis.

\section{A narrativa jornalística nos apps}

As tecnologias digitais são responsáveis pelo processo de "convergência jornalística", com implicações ao nível empresarial, tecnológico, profissional e editorial, 
propiciando uma integração de ferramentas, espaços, métodos de trabalho e linguagens antes desagregadas, "de maneira que os jornalistas produzam conteúdo que se distribuem por meio de múltiplas plataformas, mediante as linguagens próprias de cada uma delas" (SALAVERRÍA; NEGREDO, 2008, p. 45).

Essa adaptação da linguagem a cada meio e a distribuição de conteúdos multiplataformas, por meio da integração de produtos e processos, tem sido um dos grandes desafios para as organizações jornalísticas na contemporaneidade. A adaptação dos conteúdos, mediante as narrativas nos dispositivos móveis, é o movimento de interesse deste trabalho, tendo em vista que a tecnologia móvel tem transformado os conteúdos informativos em todas as suas formas (produção, distribuição e consumo).

Tal panorama pode ser vislumbrado como de transição sob o ponto de vista do campo jornalístico, desde as confluências entre formatos adaptados de outros meios de comunicação e algumas inovações específicas que já podem ser estudadas. Segundo Canavilhas e Santana (2011), apesar de alguns avanços, os conteúdos continuam a ser meras transposições da oferta existente nos meios tradicionais, num modelo de shovelware semelhante ao que ocorreu com o webjornalismo.

O jornalismo de um modo geral permanece em constante transformação e adaptação em vários aspectos, por isso são várias as tentativas e etapas das organizações jornalísticas na procura por desenvolver produtos não só adequados ao suporte, mas também que comuniquem de maneira eficiente com o público. Essas etapas de adaptações dos conteúdos jornalísticos aos meios digitais foram estudadas por vários pesquisadores, como Barbosa (2007, 2013), Cabrera González (2000), Mielniczuk (2003), Pavlik (2005) e Palacios (2002), principalmente no momento inicial de desenvolvimento do jornalismo digital. Partindo da proposta de três gerações do jornalismo na web, elaborada por Mielniczuk, Barbosa amplia o estudo para as quarta e quinta gerações. Nesta última, os dispositivos móveis são peças importantes na produção jornalística. Nosso trabalho teve foco na quinta geração do jornalismo digital e nas características desta para a construção do aplicativo da TSF Rádio Notícias.

É na quinta geração que as formas narrativas são ampliadas e que os dispositivos móveis surgem como agentes impulsionadores da inovação, "no qual a emergência dos chamados aplicativos jornalísticos autóctones para tablets são produtos paradigmáticos" (BARBOSA, 2013). A expansão dos dispositivos móveis e dos aplicativos jornalísticos gera novo processo de compreensão do jornalismo em ambiente digital, tendo em vista que, neste contexto, são os tablets e smartphones que configuram os processos jornalísticos nas redes digitais, por meio da "atuação conjunta, integrada" (Ibid., p. 33), dos bancos de dados, da medialidade e do continuum multimídia que passam a ser determinantes e configuradores dos modos de narrar no jornalismo em ambiente digital (CANAVILHAS; BACCIN; SATUF, 2017). 
Ao desenvolver um modelo de análise de potencialidades do jornalismo para plataformas móveis, Canavilhas e Santana (2011) definiram pelo menos seis caraterísticas principais as quais os conteúdos jornalísticos produzidos para as plataformas móveis devem atender: acessibilidade, instantaneidade, multimidialidade, hipertextualidade, interatividade e globalidade.

Pensando no âmbito da produção de conteúdos e na distribuição das narrativas nos aplicativos jornalísticos, Silveira e Camargo (2014) identificam, com base em estudos anteriores (ANDERSON; BELL; SHIRKY, 2013; CANAVILHAS, 2013; PALACIOS; CUNHA; PAMPLONA, 2012), cinco características específicas do jornalismo: acessibilidade (autonomia que o usuário tem para acessar não só as informações nos dispositivos móveis, mas também a facilidade deste acesso, respeitando as necessidades e preferências dos consumidores de mídia); tactilidade (acesso por meio do toque, que exige novas formatações nas formas de interação entre conteúdos e usuários); imediatismo (facilidade de portabilidade e acesso à informação, inclusive em deslocamento); geolocalização (possibilita o acesso de informações que levam em conta a localização do usuário naquele momento, ainda pouco explorada) e hibridismo (convergência da produção, distribuição e consumo de notícias em uma mesma plataforma, bem como a possibilidade de produção de textos e captura de fotos e vídeos em um mesmo dispositivo em qualquer lugar onde o usuário estiver).

Muitas são as potencialidades das narrativas jornalísticas nos dispositivos móveis. Por isso, é importante que, ao se pensar no produto jornalístico desenvolvido para dispositivos móveis, tenha-se em mente que "design e narrativa devem levar em conta as características do meio para o qual são desenvolvidos, além de estarem adaptados ao perfil do usuário" (CANAVILHAS; BACCIN; SATUF, 2017). Pois, como destacam Barbosa e Seixas (2013), os dispositivos móveis possuem gramática própria, práticas de produção adaptadas, dinâmicas de consumo individuais e modelos de negócio específicos. E ainda acrescenta-se a grande capacidade interativa, tendo em vista o uso personalizado, a geolocalização, a multimidialidade, a hipertextualidade e a acessibilidade que garantem a esses dispositivos um potencial interativo ainda maior que os "rádios companheiros". Todas essas potencialidades podem ser aproveitadas nas narrativas em aplicativos radiojornalísticos.

\section{Características das narrativas jornalísticas no aplicativo da TSF Rádio Notícias}

O aplicativo para dispositivos móveis da TSF Rádio Notícias é organizado a partir de um menu com 21 seções, das quais 12 são restritamente de caráter informativo ("Início", 
"Política", "Sociedade", "Economia", "Desporto", "Internacional”, "Cultura", "Opinião", "Vídeos", "Evasões", "Noticiários" e "Serviços"), uma de caráter persuasivo (Iniciativas ações desenvolvidas pelo Global Media Group, do qual a emissora é uma das organizações pertencentes, junto com sua audiência, como exemplo o projeto Regresso às Aulas, que premiou 15 crianças que obtiveram boas notas com $€ 500,00)$ e outras seções ("Programação", "Ficha técnica", "Newsletter", "Frequências", "Apps" e "RSS", "Contatos" e "Termos \& Privacidade") são de caráter informativo, mas não jornalístico.

No aplicativo, a observação se dá pela comparação com o site da TSF Rádio Notícias $^{2}$. Na semana de análise, entre 11 e 17 de outubro, as narrativas jornalísticas não apresentaram nenhuma adaptação de conteúdo, apenas a arquitetura das notícias foi adequada ao dispositivo. Não houve modificações narrativas da versão web para mobile. Ainda, percebe-se que o aplicativo não apresentou conteúdos originais ou específicos, conforme as especificações delineadas por Feijóo et al. (2009). Entretanto, observou-se que a rádio procura contextualizar as informações das narrativas por meio de conteúdos aumentados, que são disponibilizados através de hipertextos e recursos multimídia. Como exemplo a matéria jornalística publicada em 12 de outubro: É este o documento que a coligação enviou ao PS. No conteúdo disponibilizado no app, encontra-se, num link, o documento na íntegra (Figura 1). Isso significa que ele amplia as informações trazidas no texto, permitindo que o ouvinte-internauta aprofunde seu conhecimento acerca do assunto.

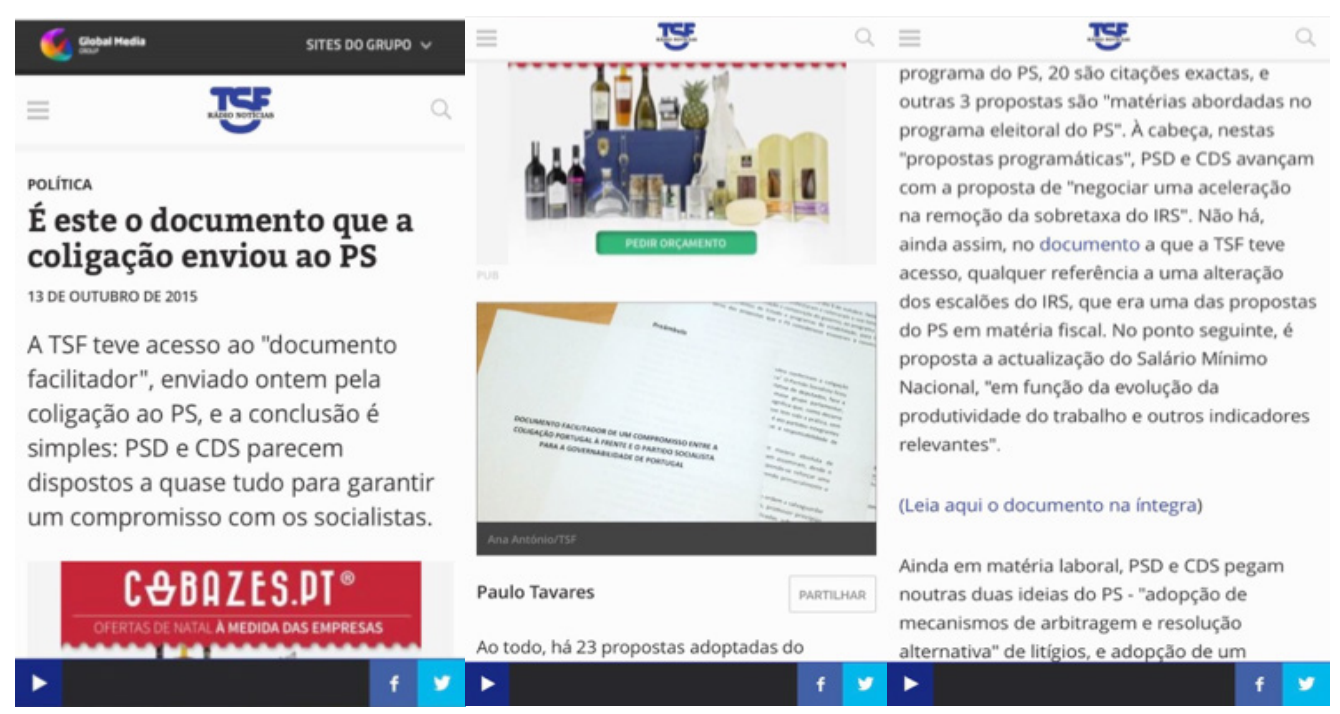

Figura 1. Narrativa com conteúdo aumentado

Fonte: Aplicativo TSF

2 Para maiores informações, consulte: <www.tsf.pt>.

$106 \frac{\text { Comunicação \& Inovação, PPGCOM/USCS }}{\text { v. 19, n. } 39 \text { (97-113) jan-abril } 2018}$ 
Outro exemplo é a matéria Volkswagen: 117 mil carros afetados em Portugal (Figura 2). Nesta, a narrativa escrita é enriquecida com uma reportagem de Nuno Serra Fernandes, valorizando a característica principal do rádio: o áudio.

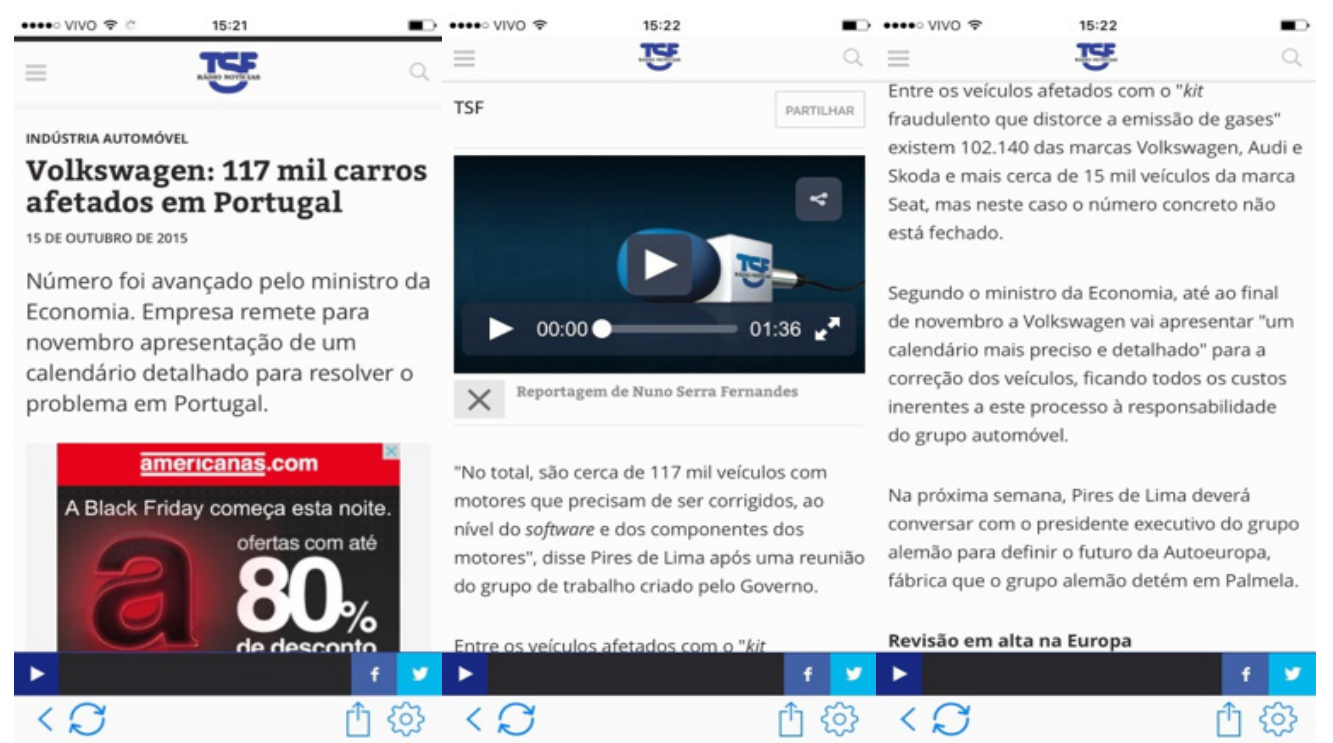

Figura 2. Narrativa enriquecida com áudio

Fonte: Aplicativo TSF

Quanto à estratégia narrativa, na notícia É com isto que temos de acabar (Figura 3), há o texto escrito com apresentação de narrativa organizada a partir de uma fotogaleria, ou seja, este é um exemplo de conteúdo dependente, pois a compreensão da matéria jornalística requer uma demonstração explicativa da situação referida no texto.

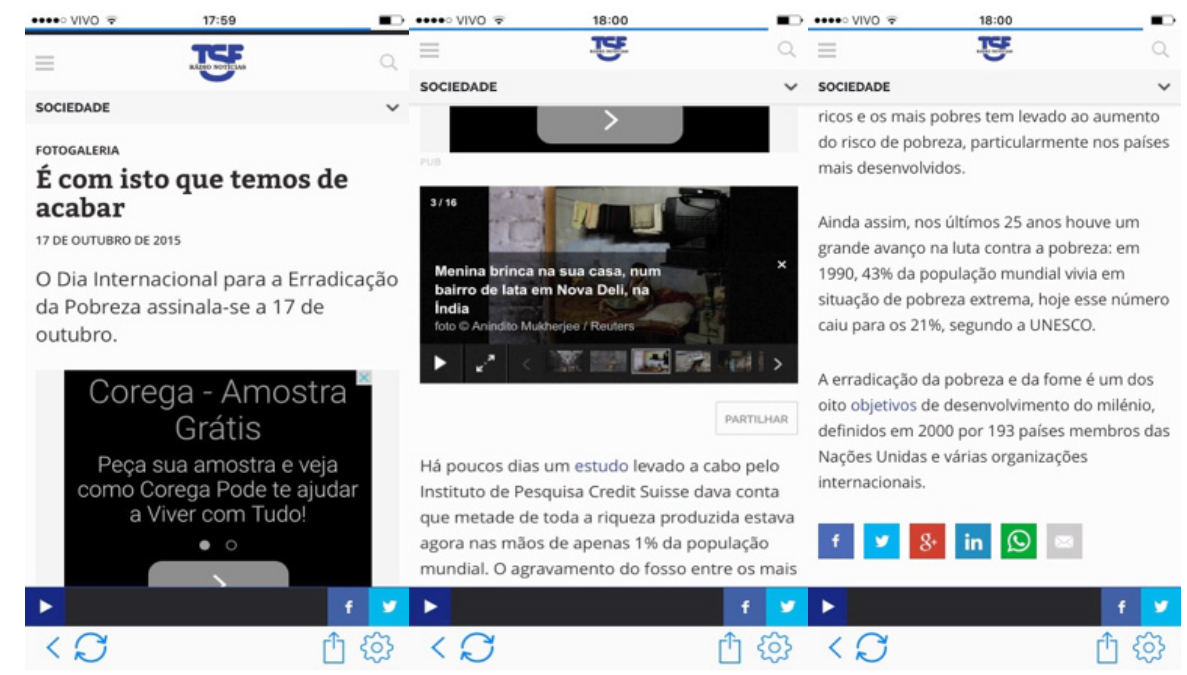

Figura 3. Narrativa organizada a partir de fotogaleria

Fonte: Aplicativo TSF 
O conteúdo do app é produzido pela equipe de profissionais da TSF Rádio Notícias, sem a interferência dos ouvintes. $\mathrm{O}$ aplicativo não oferece possibilidades de coprodução de narrativas jornalísticas, por parte dos usuários. Entretanto, uma das características mais evidenciadas no app é a capacidade de armazenamento e acesso aos conteúdos. A Rádio TSF está atenta em oferecer ao ouvinte-internauta a possibilidade de acesso aos programas radiofônicos que vão ao ar. O streaming da programação ao vivo e conteúdo complementar a ele, apresentado em multimídia, e em formato podcast. $\mathrm{Na}$ seção "Noticiários", é possível acessar as últimas emissões dos noticiários que vão ao ar de hora em hora. Os vídeos utilizados nas notícias são armazenados em seção específica, chamada "Vídeos". Um exemplo é o debate que ocorreu em 17 de setembro entre os candidatos às eleições legislativas de 2015, que está disponível no aplicativo para visualização (Figura 4), o que caracteriza a preocupação com a memória do conteúdo.

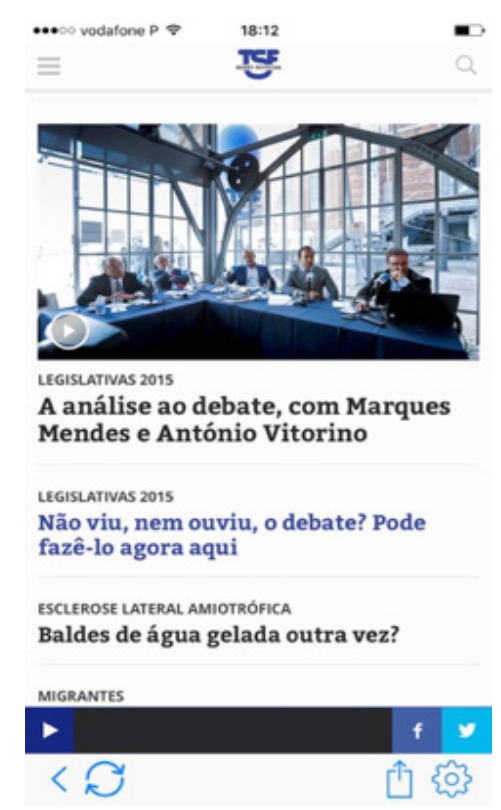

Figura 4. Seção "Vídeos" mantém armazenada as produções audiovisuais

Fonte: Aplicativo TSF

Ainda é possível analisar as características do aplicativo móvel a partir do entendimento de Barbosa (2013) sobre a quinta geração das narrativas jornalísticas. Entretanto, o app da TSF Rádio Notícias não reúne a maioria dos elementos pertencentes à quinta geração. Contudo, observa-se que existem alguns indícios dessa geração, pois há uma estruturação de narrativas em base de dados e na convergência dos meios. $O$ aplicativo da TSF não é autóctone e não há continuum multimídia, ou seja, não se configura como um app com elementos nativos do ecossistema móvel, o que seriam as mais importantes marcas da quinta geração. 
Pela análise, percebem-se diferentes potencialidades das narrativas jornalísticas em plataforma móvel, como instantaneidade, globalidade, acessibilidade, tactilidade e hibridismo. Mas a ênfase dessa observação se deu na interatividade, hipertextualidade e multimidialidade, pois se configuram mais importantes na construção das narrativas estudadas neste trabalho.

Em relação à interatividade, o app é limitado em termos de feedback do campo de produção radiofônico. A interatividade no app se dá, basicamente, porque possibilita as diferentes instâncias de seleção e participação nos conteúdos do meio. A participação ocorre por meio dos espaços para comentários logo abaixo de cada notícia no próprio aplicativo e compartilhamento de informações nas redes sociais do Facebook e do Twitter (Figura 5). Outra ação interativa oferecida pelo aplicativo é a ativação de um sistema de alerta, com o qual o ouvinte-internauta solicita a informação de que uma nova notícia foi postada no app. O usuário ainda tem disponível as possibilidades de envio de e-mail e compartilhar links por outros apps de redes sociais, por exemplo no WhatsApp, Messenger e outros aplicativos de compartilhamentos de informações que o usuário tiver no seu dispositivo (Figura 5).

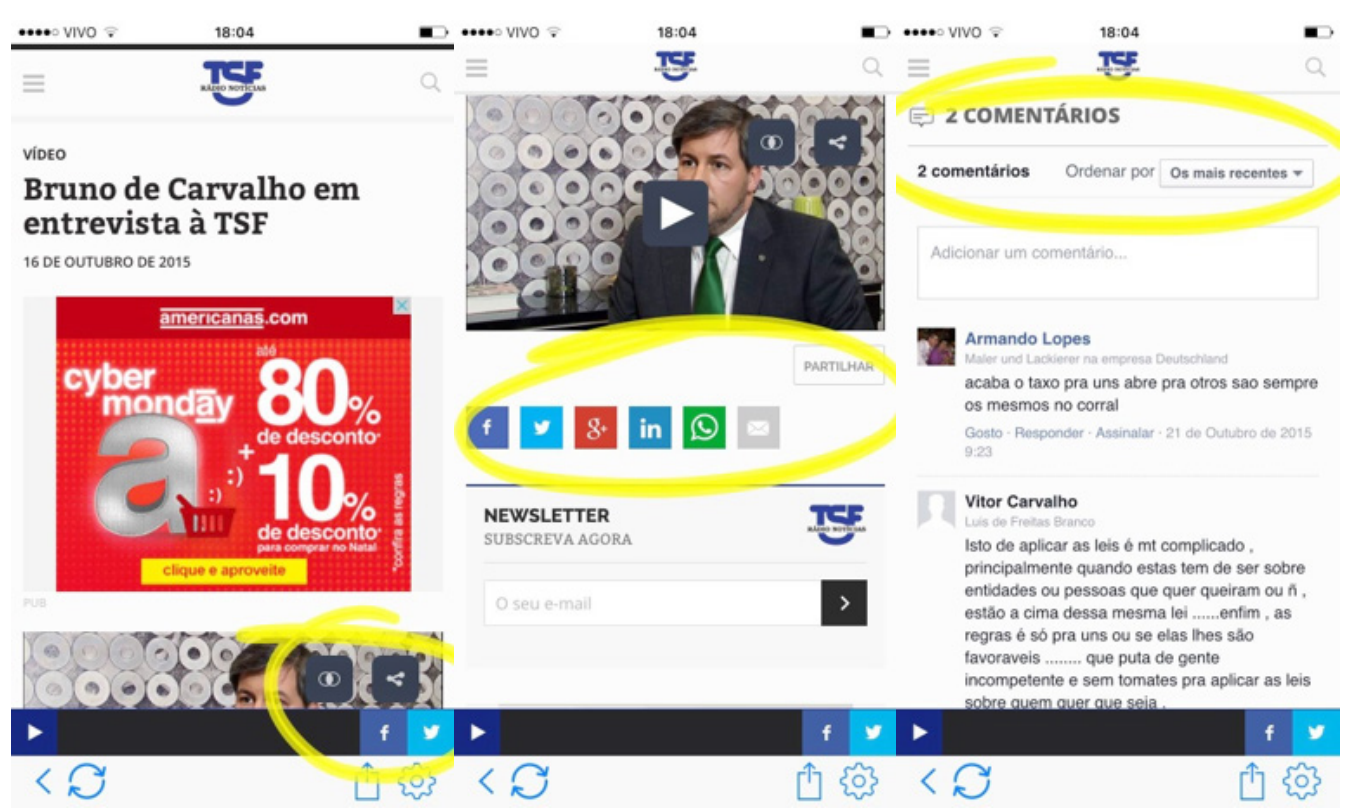

Figura 5. Opções de interatividade no aplicativo

Fonte: Aplicativo TSF

A hipertextualidade é visível em quase todas as narrativas jornalísticas analisadas na amostragem e pode ser percebida na estrutura narrativa do próprio app, quando este oferece o acesso por meio de seções. Já dentro dos conteúdos, a hipertextualidade está 
presente como estratégia narrativa que potencializa o entendimento do conteúdo por parte do ouvinte-internauta. Por fim, a multimidialidade aproveita as especificidades dos diferentes meios de comunicação, e, neste caso analisado, o app de uma emissora radiofônica, há o som, o texto e a fotografia em evidência, os quais dinamizam e potencializam uma espécie de experiências imersivas do consumo de narrativas jornalísticas, um dos objetivos dos meios que investem no ecossistema digital.

\section{Conclusão}

Tratando-se do estudo deste caso, que partiu de uma análise dos conteúdos jornalísticos da TSF Rádio Notícias, é possível inferir que o processo de transformação do rádio diante das lógicas impostas pela constituição do ecossistema digital é visível. $\mathrm{O}$ fato de ofertar ao usuário a possibilidade de acesso à emissora por meio de um aplicativo para dispositivos móveis já é um avanço, quando considerada a instância de negócios.

O investimento em tecnologia, no caso o software e suas condições de usabilidade e acessibilidade aos conteúdos, demonstra que há uma visão estratégica voltada para investimentos no campo digital, sobretudo a partir das lógicas de consumo, orientadas à ubiquidade e à instantaneidade, o que reforça a leitura do meio como companheiro, algo que não é novo para o rádio, já que foi o primeiro meio de comunicação a explorar tais potencialidades.

Entretanto, quando se analisam os conteúdos, a radiomorfose ainda está a meio caminho, no caso específico analisado. As características identificadas e analisadas a partir da epistemologia construída em torno de definições a respeito da complexidade do ecossistema digital evidenciam a necessidade da emissora em replanejar o modelo de produção de conteúdos para o app. O processo passa por uma ressignificação destes à luz de lógicas específicas da esfera digital, promovendo adaptações na construção das narrativas jornalísticas, e não apenas a transposição dos conteúdos disponíveis no site, como se percebe na comparação entre os conteúdos do app e na web. Certamente tais mudanças serão decorrentes de outras mutações, em nível laboral, ou seja, nas rotinas de trabalho e já se infere também nos profissionais envolvidos.

A TSF explora a principal característica do rádio, o som, enfatizando-o no cenário da produção de sentidos como uma experiência de multimidialidade. O ecossistema digital e, como efeito, o ecossistema móvel potencializam outra das mais importantes marcas do rádio: a interatividade, que, no caso da TSF, pode ainda ser mais bem explorada. Até existe a possibilidade de acessar e comentar os conteúdos disponibilizados, mas não há feedback da emissora no aplicativo. A multiplicação de canais de interação, como as redes 
sociais, tem como efeito ao ampliar o número de usuários coprodutores de conteúdos "all the time and everywhere". É imprescindível reconhecer este cenário como um amplo campo de oportunidades de negócio.

Por fim, pela análise apresentada, pode-se concluir que as apostas em disponibilização de apps, na incorporação de conteúdos multimidiáticos para que o usuário desfrute de uma experiência mais ampla, quem sabe até mais imersiva de consumo, são apenas algumas das medidas que necessitam ser eficientizadas no processo de reconfiguração do rádio no ecossistema digital. $\mathrm{O}$ consumo de informação será cada vez mais exigente. $\mathrm{O}$ cerne do debate para definir estratégias de captura e fidelização da audiência radiofônica no ecossistema digital está na capacidade de articular conteúdo de qualidade, tecnologia que conecta o usuário ao conteúdo (e vice-versa) e o estímulo à capacidade de ação do usuário sobre a informação. Mas tais discussões merecem novos apontamentos com a continuidade futura desta investigação.

\section{Referências}

AGUADO, J. M.; FEIJÓO, C.; MARTÍNEZ, I. J. (Coords.). La comunicación móvil. Barcelona: Gedisa, 2013.

AGUADO, J. M.; CASTELLET, A. Periodismo móvil e información ubícua. In: AGUADO, J. M.; FEIJÓO, C.; MARTÍNEZ, I. J. (Coords.). La comunicación móvil. Barcelona: Gedisa, 2013. p. 187-217.

ANDERSON, C.; BELL, E.; SHIRKY, C. Post-industrial journalism: adapting to the present. New York: Tow Center for Digital Journalism, 2012. Disponível em: <https://goo.gl/ZmDxoZ>. Acesso em: 18 abr. 2015.

BARBOSA, S. Jornalismo Digital em Base de Dados (JDBD): um paradigma para produtos jornalísticos digitais dinâmicos. 2007. 331 f. Tese (Doutorado em Comunicação e Cultura Contemporâneas) Universidade Federal da Bahia, Salvador, 2007. Disponível em: <http://migre.me/hkrS4>. Acesso em: 15 jul. 2013.

Jornalismo convergente e continuum multimídia na quinta geração do jornalismo nas redes digitais. In: CANAVILHAS, J. (Org.). Notícias e mobilidade: o jornalismo na era dos dispositivos móveis. Covilhã: LabCom, 2013. p. 33-54.

BARBOSA, S.; SEIXAS, L. Jornalismo e dispositivos móveis: percepções, usos e tendências. In: BARBOSA, S.; MIELNICZUK, L. (Orgs.). Jornalismo e tecnologias móveis. Covilhã: LabCom, 2013. p. 51-74. Disponível em: <http://migre.me/udonK>. Acesso em: 15 set. 2015.

BOLTER, J.; GRUSIN, R. Remediation: understanding new media. Cambridge: The MIT Press, 2001.

CANAVILHAS, J. O novo ecossistema mediático. Covilhã: Biblioteca On-line de Ciências da Comunicação, 2010. Disponível em <http://migre.me/udoq5>. Acesso em: 23 set. 2015. 
Notícias e mobilidade: jornalismo na era dos dispositivos móveis. Covilhã: Labcom, 2013.

CANAVILHAS, J.; BACCIN, A.; SATUF, I. Um ecossistema muito além do PC: a nova tessitura da narrativa na web. In: PEIXINHO, A. T.; ARAÚJO, B. (Org.). Narrativa e Media: géneros, figuras e contextos. 1. ed. Coimbra: Imprensa da Universidade de Coimbra, 2017. p. 317-344.

CANAVILHAS, J.; SANTANA, D. Jornalismo para plataformas móveis de 2008 a 2011: da autonomia à emancipação. Líbero, São Paulo, v. 14, n. 28, p. 53-66, dez. 2011.

CABRERA GONZÁLEZ, M. A. Convivencia de la prensa escrita y la prensa online en su transición hacia el modelo de comunicación multimídia. 2000. Disponível em: <http://migre.me/udoRE>. Acesso em: 15 mar. 2015.

CEBRIÁN HERREROS, M. O rádio no contexto da comunicação multiplataforma. Rádio-Leituras, Mariana, n. 2, ano 2, p. 69-105, jul./dez. 2011. Disponível em: <https://goo.gl/gff96F>. Acesso em: 24 nov. 2015.

DEL CANO, F. R.; GONZÁLEZ-MOLINA, S. O rádio português e espanhol na era da telefonia móvel: análise e comparativo de seus apps. Rádio-Leituras, Mariana, v. 6, n. 1, p. 37-61, jun. 2015. Disponível em: <https://goo.gl/vTk5wV>. Acesso em: 24 out. 2015.

FEIJÓO, C. et al. Exploring a heterogeneous and fragmented digital ecosystem: mobile content. Telematics \& Informatics, Amsterdam, v. 3, n. 26, p. 282-292, 2009. Disponível em: <https://goo.gl/gff96F>. Acesso em: 3 dez. 2015.

FERRARETTO, L. Alterações no modelo comunicacional radiofônico: perspectivas de conteúdo em um cenário de convergência tecnológica e multiplicidade de oferta. In: FERRARETTO, L.; KÖCKNER, L. (Eds.). E o rádio? Novos horizontes midiáticos. Porto Alegre: EdiPucrs, 2010. p. 539-556. Disponível em: <http://migre.me/udovW>. Acesso em: 3 dez. 2015.

FIDALGO, A.; CANAVILHAS, J. Todos os jornais no bolso: pensando o jornalismo na era do celular. In: RODRIGUES, C. (Ed.). Jornalismo on-line: modos de fazer. Rio de Janeiro: Sulina, 2009. p. 96-146.

FIDLER, R. Mediamorphosis: understanding new media. Thousand Oaks: Pine Forge, 1997.

KISCHINHEVSKY, M. Cultura da portabilidade e novas sociabilidades em mídia sonora: reflexões sobre os usos contemporâneos do rádio. In: INTERCOM - CONGRESSO BRASILEIRO DE CIÊNCIAS DA COMUNICAÇÃO, 31., 2008, Natal. Anais... São Paulo: Intercom, 2008. Disponível em: $<$ https://goo.gl/y3ukqw>. Acesso em: 24 nov. 2015.

KROTH, M. O rádio como dispositivo de midiatização do social: um estudo do programa João Carlos Maciel, Santa Maria, RS. 2012. 209 f. Tese (Doutorado em Ciências da Comunicação) - Universidade do Vale do Rio dos Sinos, São Leopoldo, 2012.

LOPEZ, D. Radiojornalismo hipermidiático: tendências e perspectivas do jornalismo e rádio all news brasileiro em um contexto de convergência tecnológica. 2009. 299 f. Tese (Doutorado em Comunicação e Cultura Contemporâneas) - Universidade Federal da Bahia, Salvador, 2009.

. Mutações da narrativa radiofônica em dispositivos móveis digitais: funcionalidades e potencialidades como determinantes na construção da notícia. In: CANAVILHAS, J.; SATUF, I. (Orgs.).

$112 \frac{\text { Comunicação \& Inovação, PPGCOM/USCS }}{\text { v. 19, n. } 39 \text { (97-113) jan-abril } 2018}$ 
Jornalismo para dispositivos móveis: produção, distribuição e consumo. Covilhã: Labcom, 2015. p. 343-362. Disponível em:<http://migre.me/udoxC>. Acesso em: 24 out. 2015.

MANDEL, M. Were the jobs are: the app economy. 2012. Disponível em: <http://migre.me/udoyP>. Acesso em: 29 out. 2015.

MIELNICZUK, L. Jornalismo na Web: uma contribuição para o estudo do formato da notícia na escrita hipertextual. 2003. 246 f. Tese (Doutorado em Ciências da Comunicação) - Universidade Federal da Bahia, Salvador, 2003. Disponível em: <http://migre.me/udoCk>. Acesso em: 3 abr. 2012.

ORTIZ SOBRINO, M. Á. Radio y postradio en España: una cohabitación necesaria y posible. Área abierta, Madri, v. 12, n. 2, p. 1-15, jul. 2012. Disponível em: $<$ http://migre.me/udoFr>. Acesso em: 25 out. 2015.

PALACIOS, M. Memória: Jornalismo, memória e história na era digital. In: CANAVILHAS, J. (Org.). Webjornalismo: 7 características que marcam a diferença. Covilhã: Labcom, 2014. p. 89-110.

PALACIOS, M.; CUNHA, R.; PAMPLONA, E. A tactilidade em dispositivos móveis: primeiras reflexões e ensaio de tipologias. Revista Contemporânea - Comunicação e Cultura, Salvador, v. 10, n. 3, p. 668-685, 2012. Disponível em: <http://migre.me/udoH7>. Acesso em: 24 nov. 2015.

PALACIOS, M. Jornalismo online, informação e memória: apontamentos para debate. 2002. Disponível em: $<$ http://migre.me/udoIe $>$. Acesso em: 12 maio 2013.

PAVLIK, J. El periodismo y los nuevos medios de comunicación. Barcelona: Paidós, 2005.

PRATA, N. Webradio: novos gêneros, novas formas de interação. 2008. 395 f. Tese (Doutorado em Linguística Aplicada) - Universidade Federal de Minas Gerais, Belo Horizonte, 2008. Disponível em: $<$ http://migre.me/udoJa $>$. Acesso em: 25 out. 2015.

SALAVERRÍA, R. Cibermedios: el impacto de internet en los medios de comunicación en Espanã. Sevilla: Comunicación Social Ediciones y Publicaciones, 2005.

SALAVERRÍA, R.; NEGREDO, S. Periodismo integrado: convergencia de medios y reorganización de redacciones. Barcelona: Sol90, 2008.

SALAVERRÍA, R.; GARCÍAAVILÉS, J. A.; MASIP, P. Concepto de Convergencia Periodística. In: LÓPEZ GARCÍA, X.; FARIÑA, X. P. (Eds.). Convergencia digital: reconfiguración de los medios de comunicación en España. Santiago de Compostela: Universidad de Santiago de Compostela, 2010. p. 41-64.

SCOLARI, C.; AGUADO, J. M.; FEIJÓO, C. Una ecología del medio móvil: contenidos y aplicaciones. In: AGUADO, J. M.; FEIJÓO, C.; MARTÍNEZ, I. J. (Eds.). La comunicación móvil: hacia un nuevo ecosistema digital. Barcelona: Gedisa, 2013. p. 79-106.

SCOLARI, C. et al. The Barcelona mobile cluster: actors, contents and trends. International Journal of Interactive Mobile Technologies, Kirchengasse, v. 3, n. 3, p. 47-54, July, 2009. Disponível em: $<$ http://migre.me/udoLG>. Acesso em: 7 out. 2015.

SILVEIRA, S.; CAMARGO, I. Ciberjornalismo e dispositivos móveis: características do jornalismo em mobilidade. In: CONGRESSO INTERNACIONAL DE CIBERJORNALISMO, 4., 2014, Porto, PT. Atas... Porto: ObCiber, 2014. v. 1. 